Original article

\title{
Pioglitazone and risk of bladder cancer in type 2 diabetes mellitus patients: A systematic literature review and meta-analysis of observational studies using real-world data
}

\author{
Mohammad Adil ${ }^{\mathrm{a}}$, Rashid Ali Khan ${ }^{\mathrm{a}}$, Pinaki Ghosh ${ }^{\mathrm{b}}$, Shiva Kumar Venkata ${ }^{\mathrm{b}}$, \\ Amit Dattatraya Kandhare ${ }^{\mathrm{b}}$, Manju Sharma ${ }^{\mathrm{a}, *}$ \\ a Department of Pharmacology, School of Pharmaceutical Education and Research, Jamia Hamdard (Hamdard University), New Delhi, 110062, India \\ b Department of Pharmacology, Poona College of Pharmacy, Bharati Vidyapeeth Deemed University, Pune, 411038, Maharashtra, India
}

\section{A R T I C L E I N F O}

\section{Article history:}

Received 16 June 2017

Accepted 16 August 2017

Available online 30 August 2017

\section{Keywords:}

Bladder cancer

Pioglitazone

Thiazolidinedione

Systematic review

Meta-analysis

\begin{abstract}
A B S T R A C T
Objectives: Patients with type 2 diabetes mellitus (T2DM) have a higher incidence of bladder cancer (BC); however, the evidence underlining the association between pioglitazone use and $\mathrm{BC}$ risk remains inconclusive. We conducted a systematic review and meta-analysis of observational studies to investigate the effect of pioglitazone on risk of $\mathrm{BC}$ in T2DM patients.

Methods: We searched all publications regarding risk of BC with pioglitazone use through PubMed, Web of Science and Cochrane library databases from inception to March, 2017. Pooled hazard ratio (HR) and 95\% confidence interval $(\mathrm{CI})$ were calculated using a random-effect, generic inverse variance method. Results: Total 15 observational ( 9 cohort and 6 case-control) studies were meta-analyzed. The pooled results showed a significant association between risk of BC and pioglitazone use (HR 1.20, 95\%CI 1.09$1.31 ; P<0.0001 ; I^{2}=4 \%$ ). In subgroup analysis, cumulative dose of pioglitazone ( - and $>\mathrm{mg}$ ) showed a significant association with risk of BC (HR 1.27; 95\%CI 1.05-1.54; $P=0.01 ; I^{2}=0 \%$ and $\mathrm{HR} 1.68,95 \% \mathrm{CI} 1.36-$ 2.08; $P<0 I^{2}=0 \%$ respectively). In addition, a significant association was seen with risk of $B C$ and pioglitazone treatment duration (12-24 months and $>24$ months) (HR 1.43; 95\%CI 1.19-1.71; $P=0.0001$; $I^{2}=0 \%$ and HR 1.58; 95\%CI 1.27-1.97; $P<0.0001 ; I^{2}=29 \%$ respectively). Meta-analysis of pioglitazone $v s$. rosiglitazone use, showed a significant association (HR 1.34; 95\%CI 1.05-1.71; $P=0.02 ; I^{2}=0 \%$ ) with BC risk and pioglitazone use.

Conclusion: Pioglitazone use is associated with risk of BC in T2DM patients. Risk of bladder cancer appears to be associated with higher dose and longer duration of pioglitazone use.
\end{abstract}

(c) 2017 Published by Elsevier, a division of RELX India, Pvt. Ltd on behalf of INDIACLEN.

\section{Introduction}

Thiazolidinediones (TZDs), pioglitazone and rosiglitazone are oral hypoglycaemic drugs used for the management of type 2 diabetes mellitus (T2DM). TZDs are insulin sensitizers, widely used for the management of T2DM. Pioglitazone belongs to the TZD group, target PPAR- $\gamma$ protein, a key transcription factor for adipogenesis and glucose homeostasis. ${ }^{1}$ On the other hand, patients with diabetes mellitus have a higher incidence of bladder cancer, ${ }^{2}$ but the association between TZD use and bladder cancer still a matter of debate. ${ }^{3,4}$ According to American Cancer Society, new cases of bladder cancer and deaths from bladder cancer are

\footnotetext{
* Corresponding author

E-mail addresses: manjusharma72@gmail.com, msharma@jamiahamdard.ac.in (M. Sharma)
}

expected in 2016 in the United States (US). ${ }^{5}$ Incidence of bladder cancer first time observed in a PROactive study, where 14 cases of bladder cancer were found in the pioglitazone treatment arm compared with 5 cases in the placebo group. ${ }^{6}$ Preclinical studies reported that pioglitazone and rosiglitazone treatment could develop bladder cancer in diabetic rats. ${ }^{7,8}$ It has been also found that pioglitazone exposure caused bladder cancer in male rats, while not observed in mice of either sex. However, mechanism behind the pioglitazone-induced urinary bladder cancer might not be due to PPAR- $\gamma$ interactions because of differential variation in PPAR- $\gamma$ expression subsist between the species and sex. ${ }^{9}$ Results from a 2 year nonclinical carcinogenicity studies suggested that monotherapy of rosiglitazone were not associated with the bladder cancer. ${ }^{10}$ Conversely, another study reveals that rosiglitazone remarkably prop up the bladder neoplasm occurrence in rats pretreated with hydroxybutyl (butyl) nitrosamine. ${ }^{7}$ An independent re-analysis of the RECORD trial data confirmed the original 
results, ${ }^{11}$ that rosiglitazone did not increase cardiovascular risk compared to a combination of metformin and sulfonylurea ${ }^{4}$; this has prompted the United States Food Drug Administration (US FDA) to ease some restrictions on rosiglitazone use. An interim report of longitudinal cohort study reviewed by FDA, which showed that short-term use of pioglitazone was not associated with risk of bladder cancer, whereas $>2$ years use of pioglitazone found to be linked with the bladder cancer in diabetic patients. ${ }^{12}$ Additionally, US FDA in 2011 also updated the drug labels of pioglitazone containing medicines and recommended healthcare professionals to avoid prescribing pioglitazone in patient with active bladder cancer and prescribe it with caution in patient having prior history of bladder cancer. ${ }^{13}$ Similarly, results of a restrospective cohort study performed in France also reported risk of bladder cancer in pioglitazone users among diabetic patients, ${ }^{14}$ and French Medicines Agency (Afssaps) decided to suspend the use of pioglitazone in diabetic patients. ${ }^{15}$ Conversely, a recent retrospective cohort study conducted in India documented that pioglitazone was not associated with the bladder cancer in the T2DM patients. ${ }^{16}$ Drug Technical Advisory Board (DTAB) of India in 2013 recommended deferment of pioglitazone or manufacture and sale of pioglitazone containing formulation be withdrawn and allowed to be marketed with special caution. ${ }^{17}$ Limited real world data regarding safety concern of pioglitazone use and risk of bladder cancer are equivocal and unknown. Information about pioglitazone safety would be important for indemnity and decision making when these drugs are being considered. We therefore performed a systematic literature review and meta-analysis of observational studies to provide more robust evidence regarding the risk of bladder cancer in T2DM patients with pioglitazone use.

\section{Materials and methods}

\subsection{Protocol and registration}

Our study protocol is registered on PROSPERO, the international prospective register of systematic reviews. ${ }^{18}$ The current systematic review and meta-analysis was performed according to the PRISMA (Preferred Reporting Items for Systematic Reviews and Meta-analyses) guideline. ${ }^{19}$

\subsection{Search strategies}

We performed a comprehensive literature search by using electronic databases PubMed, Web of Science and the Cochrane Central Register of Controlled Trials (CENTRAL) from inception through March, 2017 to identify relevant studies that investigated the association between pioglitazone and risk of bladder cancer in patients withdiabetes mellitus. The PubMed search strategy used the following text words or Medical Subject Headings (Mesh): “diabetes mellitus", “diabetes", "bladder cancer", "urinary bladder neoplasms", "pioglitazone”, "glitazone”, and "thiazolidinediones". Manual searches were also performed on Google Scholar and bibliographies of included studies and previous reviews were also examined to identify additional relevant publications. The literature search was performed with no time-frame restrictions. Language other than English was not included in analysis.

\subsection{Study selection}

Study selection was based on an initial screen of identified titles and abstracts and a second screen of full-text articles. Studies were considered eligible if they met the following criteria: (1) the study design was an observational study (Cohort, nested case-control or case control); (2) the exposure of interest was pioglitazone (3) the outcome of interest was bladder cancer incidence or effect of pioglitazone on bladder cancer; (4) patients with T2DM; (5) reported unadjusted or adjusted estimates [hazard ratio (HR) or odds ratio (OR)] of the association between exposure and outcome, and the corresponding 95\% confidence interval (CI), or sufficient raw data to allow their calculation.

\subsection{Data extraction}

Three independent reviewers (MA, RK and SV) extracted the abstract judiciously according to inclusion criteria. Any discrepancies were arbitrated by the third senior reviewers (AK, PG, and MS) until consent is achieved on every issue. A standard data extraction format was used to collect study information including; name of the first author, year of the publication, age, percentage of male, settings, country, database used, study population, exposure and outcome ascertainment, number of cases/control, exposure $v s$. comparison, duration of follow up, dose and duration of pioglitazone therapy, unadjusted and fully adjusted HR or OR and their 95\% CI, and adjusted variables.

\subsection{Quality assessment}

Two reviewers (MA and RK) independently assessed the quality of each study by using Newcastle-Ottawa Scale (NOS), as recommended by the Cochrane Non-Randomized Studies Methods Working Group. ${ }^{20}$ The NOS consists of three parameters of quality: selection, comparability, and exposure (case-control studies) or outcome (cohort studies). The NOS based on star system (with a maximum of nine stars) assigns a maximum of four stars for selection, two for comparability, and three for exposure/outcome. We considered studies with a score of 6 or greater as high quality.

\subsection{Statistical analysis}

The adjusted effect estimates (HR, or OR) and associated 95\% CI for the bladder cancer outcomes and use of pioglitazone were extracted. All analyses were conducted on the natural log scale and standard errors (SE) derived from the formula: [log (95\%CI, upper limit)-log (95\%CI, lower limit)]/3.92. ${ }^{21}$ The OR was considered as equivalent to HR when the disease of interest is not common. ${ }^{22} \mathrm{We}$ used HR as the common measure of association across studies. Because of the clinical heterogeneity inherent in our data, we used random effects models (DerSimonian and Laird) for meta-analyses of extracted $\log \mathrm{HR}$ and their SE. ${ }^{23}$ Generic inverse variance outcome type was used to pool HR with $95 \% \mathrm{CI}$ of included studies. Statistical heterogeneity was assessed using the $I^{2}$ statistic, with results ranging from 0 to $100 \%$ and values of 25,50 and $75 \%$ representing low, moderate and high levels of heterogeneity, respectively. ${ }^{24}$ Primary analysis focused on assessing the risk of bladder cancer among pioglitazone users. Predefined subgroup meta-analysis was performed for the effect of pioglitazone cumulative dose and duration on risk of bladder cancer. A sensitivity analysis was conducted to assess the influence of individual studies on the pooled result, by excluding each study one by one and recalculating the combined HR on the remaining studies analysis. We also excluded those studies which mentioned only unadjusted estimates and poor quality (score $<6$ ) of study according to NOS. The potential publication bias was performed by using a funnel plot for asymmetry and was examined by using the Begg's adjusted rank correlation test and Egger's linear regression test, if $>10$ studies were included in the analysis of the primary outcomes. $^{25,26}$ All the statistical analysis was conducted with Review Manager 5.3 (Nordic Cochrane Centre, Cochrane Collaboration, 2014) and $\mathrm{R}$ software, version 3.3.2 ( $\mathrm{R}$ Foundation for Statistical Computing, Vienna, Austria), using the packages 
"meta". ${ }^{27}$ All $p$ values were considered statistically significant when $<0.05$.

\section{Results}

\subsection{Literature search and study inclusion}

The PRISMA flow diagram summarizing the process of study selection is shown in Fig. 1. The electronic search identified 677 potentially relevant records, of which 620 were excluded after screening the title and abstract. The remaining 57 full-text articles were assessed for eligibility, and 41 were further excluded due no information on pioglitazone use, bladder cancer, study design, and duplicates. Total 16 articles were include for the systematic literature review and further excluded 1 study because of absence of adjusted estimate for the association between risk of bladder cancer and pioglitazone use. Finally, 15 studies were included in the meta-analysis.

\subsection{Study characteristics and quality assessment}

Of 16 observational studies, 10 studies ${ }^{12,14,28-35}$ were cohort and 6 studies ${ }^{36-41}$ were case-control, with 5 of these being case-control studies nested within cohorts. ${ }^{36-40}$ The general characteristics of each study are reported in Table 1 . Among the 16 studies, 2 were conducted in USA, ${ }^{12,34} 5$ in Taiwan ${ }^{29,32,37-39}, 3$ in Korea ${ }^{33,40,41}, 1$ in Japan, ${ }^{31} 4$ in $\mathrm{UK}^{28,30,35,36}$, and 1 in France. ${ }^{14} 2$ studies reported two drugs pairs, pioglitazone vs. no pioglitazone use and pioglitazone vs. rosiglitazone use. ${ }^{35,36}$ Mamtani and colleagues ${ }^{28}$ reported data on pioglitazone vs. rosiglitazone use, total 15 studies, ${ }^{12,14,29-41}$ reported data on piogltazone vs. no pioglitazone use. More comprehensive study characteristics are provided in the Appendix Tables A1 and A2.

The quality assessment of the included studies is shown in Appendix Table A3. The NOS results showed that the average score was 7.7 (range 4-9) for cohort studies and 7.6 (range 6-8) for casecontrol studies. From 16 observational studies, 1 cohort study ${ }^{31}$ did not report adjusted estimates for the risk of bladder cancer and low quality study according to NOS excluded from the meta-analysis. Summary of meta-analyses of included studies shown in Table 2.

\subsection{Pioglitazone use and risk of bladder cancer}

We identified 14 eligible observational studies, among these, 8 were cohort $^{12,14,29,30,32-35}$ and 6 were case-control studies ${ }^{36-41}$ included total 24,70397 patients with bladder cancer cases. Fig. 2 represents the pooled HR of the association between pioglitazone use and risk of bladder cancer. Results from the forest plot showed a significant association between risk of bladder cancer and pioglitazone users vs. non users (HR $=1.20$; 95\% CI 1.09-1.31; $\left.P<0.0001 ; I^{2}=4 \%\right)$. When restricting the analysis only to cohort studies, the risk estimate was almost similar $(\mathrm{HR}=1.19 ; 95 \% \mathrm{CI}$ $\left.1.09-1.31 ; P=0.0001 ; I^{2}=0 \%\right)$, whereas results from case-control analysis showed a non-significant association between risk of bladder cancer and pioglitazone users $v s$. non users ( $\mathrm{HR}=1.25 ; 95 \%$ CI $0.93-1.68 ; P=0.14 ; I^{2}=28 \%$ ).

\subsection{Risk of bladder cancer with increasing cumulative pioglitazone dose}

Total 8 studies $^{12,14,29,32,35-37,39}$ reported data regarding cumulative dose of pioglitazone user vs. non users. Only 6 studies $^{12,14,29,32,35,36}$ were eligible for the meta-analysis. Patients who received a cumulative dose of pioglitazone ranged from $-\mathrm{mg}$ and $>\mathrm{mg}$ showed a significant association with risk of bladder cancer $\left(\mathrm{HR}=1.27 ; 95 \% \mathrm{CI} 1.05-1.54 ; P=0.01 ; I^{2}=0 \%\right.$ and $\mathrm{HR}=1.68 ; 95 \% \mathrm{CI}$ 1.36-2.08; $P<0 I^{2}=0 \%$ respectively), whereas no association ( $\left.\mathrm{HR}=1.13 ; 95 \% \mathrm{CI} 0.95-1.35 ; P=0.16 ; I^{2}=0 \%\right)$ was found in patients who received a cumulative dose of pioglitazone $<\mathrm{mg}$ (Fig. 3 ).

\subsection{Risk of bladder cancer with increasing cumulative pioglitazone duration}

Of 10 observational studies ${ }^{12,14,29,30,32,35-38,40}$ reporting data regarding cumulative duration of pioglitazone users vs. non users, only 9 studies ${ }^{12,14,29,32,35-38,40}$ were eligible for the meta-analysis. 2

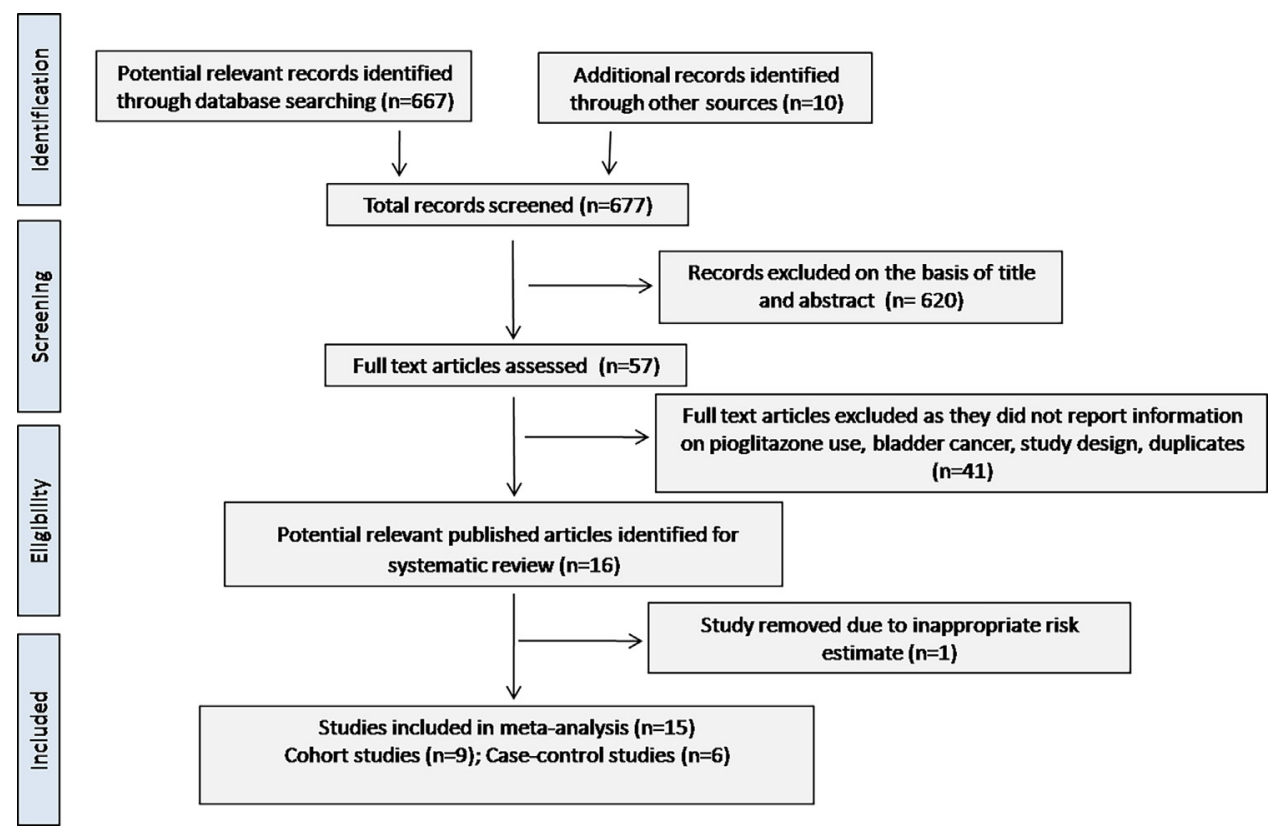

Fig. 1. PRISMA flow diagram of study selection process. 
Table 1

Characteristics of included studies.

\begin{tabular}{|c|c|c|c|c|c|c|c|c|c|c|c|}
\hline Author, year & Study design & Data source & Country & $\begin{array}{l}\text { Study } \\
\text { period }\end{array}$ & $\begin{array}{l}\text { No.of } \\
\text { participants }\end{array}$ & $\begin{array}{l}\text { Male } \\
(\%)\end{array}$ & $\begin{array}{l}\text { Age, } \\
\text { (year) }\end{array}$ & $\begin{array}{l}\text { Follow-up } \\
\text { (years) }\end{array}$ & $\begin{array}{l}\text { Drug } \\
\text { comparison }\end{array}$ & $\begin{array}{l}\mathrm{BC} \\
\text { cases }\end{array}$ & $\begin{array}{l}\text { Adjusted } \\
\text { estimates (95\% } \\
\mathrm{CI})^{1}\end{array}$ \\
\hline Lewis, $2011^{12}$ & Longitudinal cohort & KPNC & USA & $\begin{array}{l}1997- \\
2008\end{array}$ & 193099 & 53 & $\geq 40$ & $\begin{array}{c}\text { Pio: } \\
\text { Median- } \\
9.3 \\
\text { No Pio: } \\
\text { Median- } \\
6.2\end{array}$ & $\begin{array}{l}\text { Pio vs. no } \\
\quad \text { Pio }\end{array}$ & 881 & $1.20(0.90-1.50)$ \\
\hline Mamtani, $2012^{28}$ & Retrospective cohort & THIN & UK & $\begin{array}{c}2000- \\
2010\end{array}$ & 88369 & 56 & $\begin{array}{c}\text { Pio: } \\
\text { Mediun- } \\
62 \\
\text { Rosi: } \\
\text { Median- } \\
63\end{array}$ & $\begin{array}{c}\text { Pio: } \\
\text { Median- } \\
2.4 \\
\text { Rosi: } \\
\text { Median- } \\
4.4\end{array}$ & Pio vs. Rosi & 127 & $1.14(0.79-1.66)$ \\
\hline Neumann, $2012^{14}$ & $\begin{array}{c}\text { Population-based } \\
\text { cohort }\end{array}$ & PMSI, SNIIRAM & France & $\begin{array}{c}2006- \\
2009\end{array}$ & 1491060 & 53 & $\begin{array}{l}\text { Range: } \\
40-79\end{array}$ & Mean 3.1 & $\begin{array}{l}\text { Pio vs. no } \\
\quad \text { Pio }\end{array}$ & 2016 & $1.22(1.05-1.43)$ \\
\hline Tseng, $2012^{29}$ & $\begin{array}{l}\text { Population-based } \\
\text { cohort }\end{array}$ & $\mathrm{NHI}$ & Taiwan & $\begin{array}{c}2006- \\
2009\end{array}$ & 54928 & NR & NR & Max-4 & $\begin{array}{l}\text { Pio vs. no } \\
\quad \text { Pio }\end{array}$ & 165 & $1.30(0.66-2.58)$ \\
\hline Wei, $2013^{30}$ & $\begin{array}{c}\text { Population-based } \\
\text { cohort }\end{array}$ & GPRD & UK & $\begin{array}{c}2001- \\
2010\end{array}$ & 207714 & 57 & Mean: 63 & $\begin{array}{c}\text { Pio: Mean- } \\
3.5 \\
\text { No Pio: } \\
\text { Mean-5.3 }\end{array}$ & $\begin{array}{l}\text { Pio vs. no } \\
\quad \text { Pio }\end{array}$ & 869 & $1.16(0.83-1.62)$ \\
\hline Fujimoto, $2013^{31}$ & Retrospective cohort & Kitano Hospital & Japan & $\begin{array}{c}2000- \\
2011\end{array}$ & 21335 & NR & NR & NR & $\begin{array}{l}\text { Pio vs. no } \\
\quad \text { Pio }\end{array}$ & 170 & NR \\
\hline Lee, $2014^{32}$ & $\begin{array}{l}\text { Population-based } \\
\text { cohort }\end{array}$ & $\mathrm{NHI}$ & Taiwan & $\begin{array}{c}2003- \\
2009\end{array}$ & 34970 & 47 & NR & 4 & $\begin{array}{l}\text { Pio vs. no } \\
\quad \text { Pio }\end{array}$ & 84 & $1.03(0.45-2.35)$ \\
\hline Jin, $2014^{33}$ & $\begin{array}{l}\text { Population-based } \\
\text { retrospective cohort }\end{array}$ & $\begin{array}{c}\text { Tertiary } \\
\text { referral } \\
\text { hospitals }^{\#}\end{array}$ & Korea & $\begin{array}{c}2005- \\
2011\end{array}$ & 113193 & 52 & Mean: 63 & NR & $\begin{array}{l}\text { Pio vs. no } \\
\quad \text { Pio }\end{array}$ & 267 & $1.13(0.77-1.67)$ \\
\hline Lewis, $2015^{34}$ & $\begin{array}{l}\text { Population-based } \\
\text { cohort }\end{array}$ & KPNC & USA & $\begin{array}{c}1997- \\
2012\end{array}$ & 193099 & 53 & $\geq 40$ & $\begin{array}{c}\text { Pio: } \\
\text { Median-6.1 } \\
\text { No Pio: } \\
\text { Median-7.2 }\end{array}$ & $\begin{array}{l}\text { Pio vs. no } \\
\quad \text { Pio }\end{array}$ & 1261 & $1.06(0.89-1.26)$ \\
\hline Tuccori, $2016^{35}$ & $\begin{array}{l}\text { Population-based } \\
\text { cohort }\end{array}$ & CPRD & UK & $\begin{array}{c}2000- \\
2013\end{array}$ & 145806 & 57 & Mean: 64 & Mean: 4.7 & $\begin{array}{c}\text { Pio vs. no } \\
\text { TZD } \\
\text { Pio vs. Rosi }\end{array}$ & $\begin{array}{l}551 \\
110\end{array}$ & $\begin{array}{l}1.63(1.22-2.19) \\
1.48(1.01-2.16)\end{array}$ \\
\hline Azouzlay, $2012^{36}$ & $\begin{array}{l}\text { Nested-case control } \\
\text { within cohort }\end{array}$ & GPRD & UK & $\begin{array}{l}1988- \\
2009\end{array}$ & 115727 & 81 & Mean: 69 & $\begin{array}{c}\text { Pio: Mean- } \\
4.8 \\
\text { Rosi: } \\
\text { Mean-4.8 }\end{array}$ & $\begin{array}{l}\text { Pio vs. no } \\
\text { TZD }\end{array}$ & $\begin{array}{c}\text { BC } \\
\text { cases/ } \\
\text { Control } \\
376 / \\
6699\end{array}$ & $1.83(1.1-3.05)$ \\
\hline Chang, $2012^{37}$ & $\begin{array}{l}\text { Nested-case control } \\
\text { within cohort }\end{array}$ & $\mathrm{NHI}$ & Taiwan & $\begin{array}{c}2000- \\
2007\end{array}$ & 606583 & 64 & Mean: 71 & $\begin{array}{l}\text { Median: } \\
7.9\end{array}$ & $\begin{array}{c}\text { Pio vs. Rosi } \\
\text { Pio vs. no } \\
\text { Pio }\end{array}$ & $\begin{array}{c}55 / 842 \\
1583 / \\
6308\end{array}$ & $\begin{array}{c}1.60(0.88-2.90) \\
0.95(0.7-1.29)\end{array}$ \\
\hline Hsiao, $2013^{\$, 38}$ & $\begin{array}{l}\text { Nested-case control } \\
\text { within cohort }\end{array}$ & $\mathrm{NHI}$ & Taiwan & $\begin{array}{l}1997- \\
2008\end{array}$ & NR & 68 & Mean: 66 & Mean: 3.6 & $\begin{array}{l}\text { Pio vs. no } \\
\quad \text { Pio }\end{array}$ & $\begin{array}{l}3412 / \\
17060\end{array}$ & $1.62(0.92-2.85)$ \\
\hline Kuo, $2014^{39}$ & $\begin{array}{l}\text { Nested-case control } \\
\text { within cohort }\end{array}$ & $\mathrm{NHI}$ & Taiwan & $\begin{array}{c}2002- \\
2009\end{array}$ & 64745 & 62 & Mean: 69 & NR & $\begin{array}{l}\text { Pio vs. no } \\
\quad \text { Pio }\end{array}$ & $\begin{array}{l}259 / \\
1036\end{array}$ & $1.20(0.58-2.49)$ \\
\hline Han, $2016^{40}$ & $\begin{array}{l}\text { Nested-case control } \\
\text { within cohort }\end{array}$ & NHIS-NSC & Korea & $\begin{array}{c}2003- \\
2013\end{array}$ & 47738 & 69 & $\geq 40$ & $\begin{array}{l}\text { Median: } \\
7.9\end{array}$ & $\begin{array}{l}\text { Pio vs. no } \\
\text { Pio }\end{array}$ & $85 / 850$ & $0.75(0.26-2.15)$ \\
\hline Song, $2012^{41}$ & $\begin{array}{c}\text { Retrospective, } \\
\text { matched case- control }\end{array}$ & $\begin{array}{l}\text { Severance } \\
\text { Hospital }\end{array}$ & Korea & $\begin{array}{c}2005- \\
2011\end{array}$ & NR & 84 & Mean: 69 & NR & $\begin{array}{l}\text { Pio vs. no } \\
\quad \text { Pio }\end{array}$ & $\begin{array}{l}329 / \\
658\end{array}$ & $\begin{array}{c}2.09(0.26- \\
16.81)\end{array}$ \\
\hline
\end{tabular}

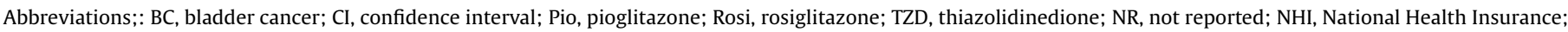

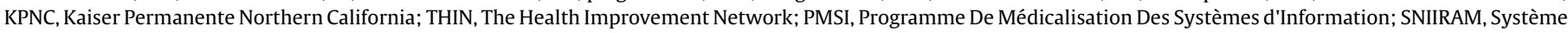

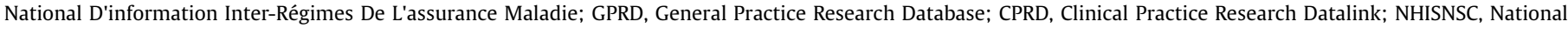
Health Insurance Service-National Sample Cohort.

1 Risk estimates are as follows: hazard ratio [12,14,28-36], odd ratio [37-41].

\# Medical Centre, Severance Hospital, Asan Medical Center, and Seoul St. Mary's Hospital.

$\$$ Adjusted data calculated from pooling current/recent/past users estimates.

studies required to pool their estimates into one estimate by using inverse variance method, i) $2-3$ years and $\geq 3$ years ${ }^{37}$; ii) $\leq 3$ months and 3-12 months. ${ }^{40}$ Results from the summary of metaanalysis showed a significant association with risk of bladder cancer and pioglitazone treatment ranged from 12 to 24 months and $>24$ months $\left(\mathrm{HR}=1.43 ; 95 \%\right.$ CI $1.19-1.71 ; P=0.0001 ; I^{2}=0 \%$ and $\mathrm{HR}=1.58 ; 95 \% \mathrm{CI} 1.27-1.97 ; P<0.0001 ; I^{2}=29 \%$ respectively), whereas pioglitazone treatment for $<12$ months showed no association with risk of bladder cancer and pioglitazone treatment (HR=1.11; 95\% CI 0.90-1.37; $P=0.31 ; I^{2}=42 \%$ ) (Fig. 4).

\subsection{Pioglitazone use vs. rosiglitazone use and risk of bladder cancer}

Among 3 studies, 2 were cohort $^{28,35}$ and 1 case-control $^{36}$ studies included patients and 292 bladder cancer cases. After pooling data, an increased risk of bladder cancer with pioglitazone 
Table 2

Summary of the meta-analysis.

\begin{tabular}{|c|c|c|c|c|c|c|c|c|c|}
\hline & \multirow[t]{2}{*}{ No. of studies } & \multirow[t]{2}{*}{ Total no. of $\mathrm{BC}$ cases } & \multirow[t]{2}{*}{ Total no. of patients } & \multicolumn{2}{|c|}{ Heterogeneity } & \multirow[t]{2}{*}{ Model } & \multicolumn{3}{|c|}{ Pooled estimates } \\
\hline & & & & $I^{2}(\%)$ & $P$ value & & HR & $95 \% \mathrm{CI}$ & $P$ \\
\hline Pio vs. no Pio & 14 & 12,138 & 24,70397 & 4 & 0.41 & Random effect & 1.20 & $1.09-1.31$ & $<0.0001$ \\
\hline Pio cumulative dose (mg) & - & - & - & & & & & & \\
\hline$<10,500$ & 6 & & & 0 & 0.84 & Random effect & 1.13 & $0.95-1.35$ & 0.16 \\
\hline $10,501-28,000$ & 4 & & & 0 & 0.66 & Random effect & 1.27 & $1.05-1.54$ & 0.01 \\
\hline$>28,000$ & 4 & & & 0 & 0.61 & Random effect & 1.68 & $1.36-2.08$ & $<0.00001$ \\
\hline Pio cumulative duration (months) & - & - & - & & & & & & \\
\hline$<12$ & 9 & & & 42 & 0.09 & Random effect & 1.11 & $0.90-1.37$ & 0.31 \\
\hline $12-24$ & 6 & & & 0 & 0.83 & Random effect & 1.43 & $1.19-1.71$ & 0.0001 \\
\hline$>24$ & 6 & & & 29 & 0.22 & Random effect & 1.58 & $1.27-1.97$ & $<0.0001$ \\
\hline Pio vs. Rosi & 3 & 292 & & 0 & 0.51 & Random effect & 1.34 & $1.05-1.71$ & 0.02 \\
\hline
\end{tabular}

Abbreviations: BC, bladder cancer; HR, hazard ratio; CI, confidence interval; Pio, pioglitazone; Rosi, rosiglitazone.

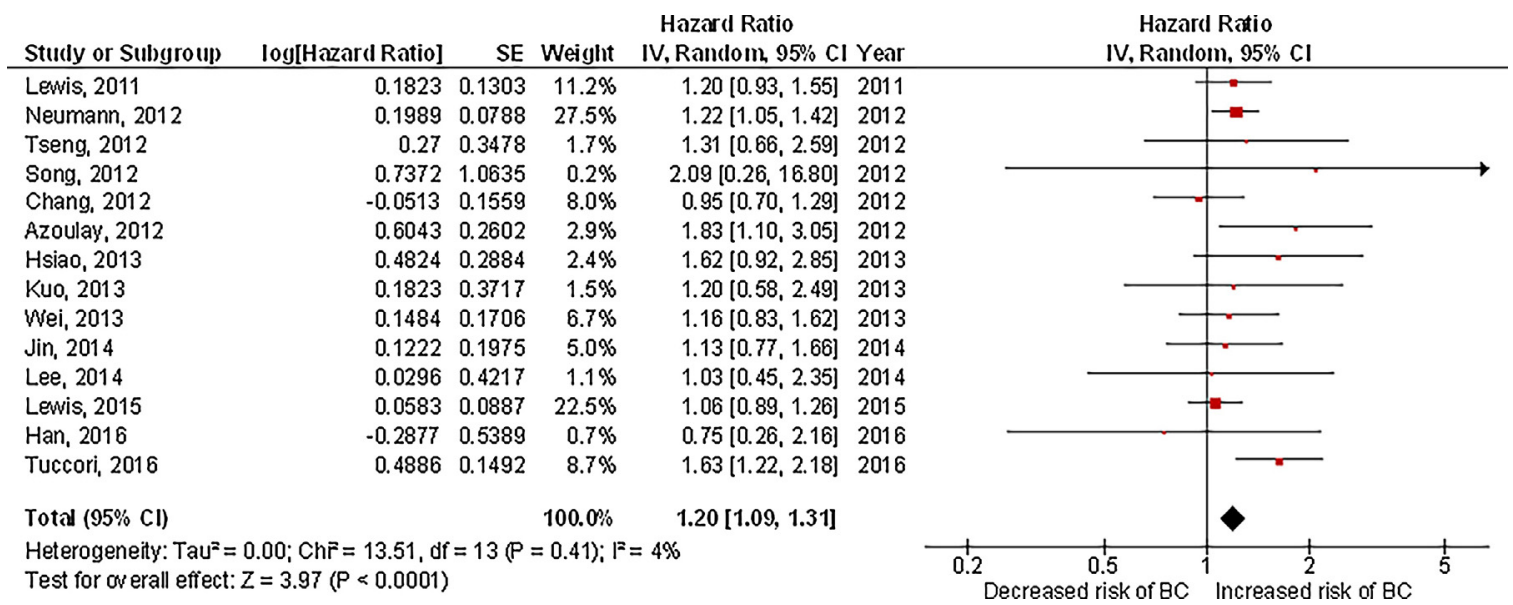

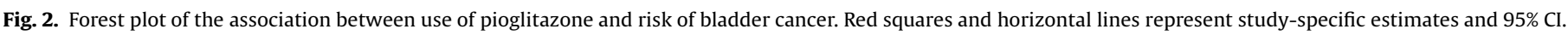

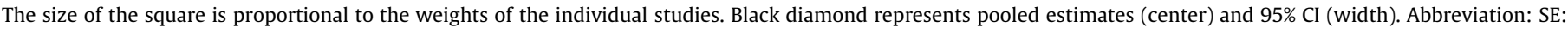
standard error, IV: inverse variance, BC: bladder cancer.

use was found. Association between risk of bladder cancer and pioglitazone use was significant ( $\mathrm{HR}=1.34 ; 95 \%$ CI 1.05-1.71; $P=0.02 ; I^{2}=0 \%$ ) (Appendix Fig. A1).

\subsection{Sensitive analysis and publication bias}

In the "leave-one-out" sensitive analysis when omitting one study, ${ }^{35}$ resulted in loss of statistical significance of the pooled estimates $\quad\left(\mathrm{HR}=1.25 ; \quad 95 \% \quad \mathrm{CI} \quad 0.91-1.72 ; \quad P=0.16 ; \quad I^{2}=0 \%\right)$ (Appendix Fig. A1). Otherwise, we did not find any major changes in direction or magnitude of the summary estimates and $P$ values of heterogeneity in the other analyses. Only pioglitazone use vs. no pioglitazone use subgroup analysis was eligible for an asymmetry test for publication bias because there were $<10$ studies in any other particular meta-analysis. The shape of the funnel plots for included studies seemed asymmetrical. Begg's adjusted rank correlation and Egger's linear regression tests showed no significant evidence of publication bias (Begg's test $P=0.87$; Egger's test $P=0.49$ ) (Appendix Fig. A2).

\section{Discussion}

This systematic review and meta-analysis analyses the effect of pioglitazone on the risk of bladder cancer in patients with T2DM. The summary results from the studies indicated that pioglitazone use was significantly associated with increased risk of bladder cancer.

TZD activates the PPAR- $\gamma$ nuclear receptors and improves insulin sensitivity. Results from the laboratory studies suggested that PPAR- $\gamma$ agonist might have anti-cancer properties, such as cell-cycle arrest, induction of apoptosis and inhibition of cell invasion. ${ }^{42}$ In contrast, preclinical studies indicate that PPAR- $\gamma$ agonists can potentiate tumerogenesis. ${ }^{43}$ Few animal studies also have examined pioglitazone exposure in relation to development of bladder tumor. ${ }^{8}$ However, mechanisms underlying carcinogenic effect of pioglitazone yet not completely explored.

Few unmeasured confounders such as smoking, duration of diabetes, COPD, kidney disease, urinary tract disease may be linked with the TZD use and risk of bladder cancer. An increased bladder cancer risk has been consistently associated with smoking and renal transplant population. ${ }^{44,45}$ Data from the cohort included in 8 -year interim to the FDA suggested that proteinuria test results were positively associated $(\mathrm{HR}=2.45,95 \% \mathrm{CI} 2.12-2.82)$ with bladder cancer risk. Proteinuria testing may be a potential confounder in studies of the association between pioglitazone use and risk of bladder cancer. ${ }^{46}$ However, growing body of evidences reported no risk of bladder cancer development in the diabetic patients who are treated with pioglitazone use. ${ }^{32,34}$ In contrast, several clinical studies have suggested significant association of pioglitazone use with risk of bladder cancer. ${ }^{14,35}$ When we examined the association between bladder cancer risk 


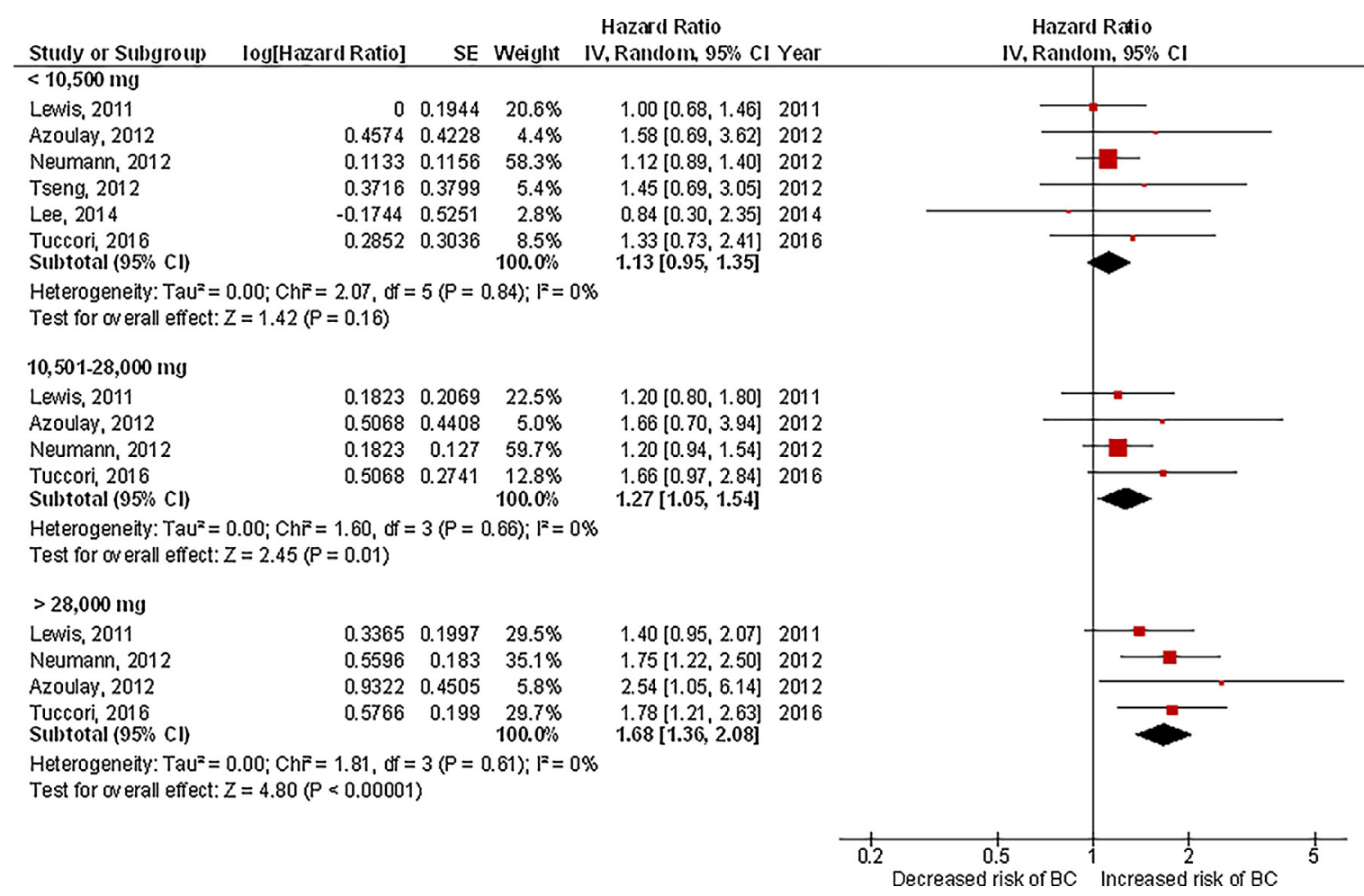

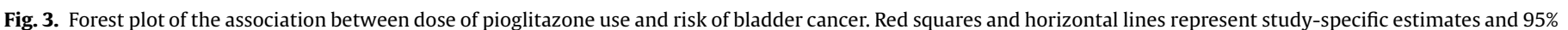

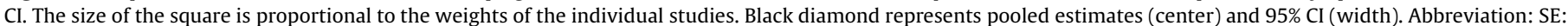
standard error, IV: inverse variance, BC: bladder cancer.

and increasing levels of pioglitazone exposure, the risk of bladder cancer increased with increasing duration and cumulative dose of pioglitazone use. Dose $<\mathrm{mg}$ and duration $<12$ months are not associated with risk of bladder cancer, whereas dose $-\mathrm{mg}$ and $>\mathrm{mg}$ as well as duration $12-24$ and $>24$ months of pioglitazone exposure are associated with risk of bladder cancer. In line with our findings, few studies also suggested that dose $<\mathrm{mg}$ and duration $<12$ months of pioglitazone was not associated with risk of bladder cancer in T2DM patients. $^{32}$ On the other hand, increasing cumulative dose and duration of pioglitazone use are strongly associated with risk of bladder cancer. These findings are congruence with our current results. Furthermore, recently Korhonen and colleagues ${ }^{47}$ conducted a retrospective cohort study in T2DM patients using datasets from four European countries to evaluate the association between pioglitazone use and risk of bladder cancer. Results from this cohort study showed a non-significant association between risk of bladder cancer and pioglitazone use $v$ s. use $(\mathrm{HR}=0.99,95 \% \mathrm{CI} 0.75-1.30)$ and $(\mathrm{HR}=1.00$, 95\% CI 0.83-1.21) in the nearest and multiple match cohorts, respectively. Similarly, increase in cumulative dose $(>\mathrm{mg})$ and duration ( $>48$ months) of pioglitazone exposure was also not significantly associated with risk of bladder cancer $(H R=0.65,95 \%$ CI $0.33-1.26$ and $\mathrm{HR}=0.86,95 \% \mathrm{CI} 0.44-1.66$, respectively) in the nearest match cohort.

Clinically, TZDs may be a risk factor for bladder cancer in patients with diabetes, but findings from clinical and epidemiological studies are inconsistent. For instances, analysis from a population-based retrospective cohort study of 11,3193 patients with diagnosis of T2DM, TZD exposure seems to reduce the risk of overall cancer including bladder cancer (in a dose dependent manner). ${ }^{48}$

Additionally, in the subgroup analysis stratified by head to head comparison between the pioglitazone use $v s$. rosglitazone use and risk of bladder cancer, our summary effect estimates showed significant trends towards the increased risk of bladder cancer among diabetic patients using pioglitazone compared with the risk in those using rosiglitazone. However, a previous meta-analysis conducted in 2 observational studies showed non-significant effect when compared pioglitazone use $v s$. rosiglitazone and risk of bladder cancer. ${ }^{49}$ This finding reflects the importance of extensive real world evidence as the results became discernable after the inclusion of study conducted by Tuccori and colleagues. ${ }^{35}$

Considering an increased risk of bladder cancer with pioglitazone, the U.S. Food and Drug Administration (FDA) recommends that healthcare professionals should not prescribe pioglitazone in patients with active bladder cancer. Moreover, the benefits of glycemic control vs. unknown risks for cancer recurrence with pioglitazone should be considered in patients with a prior history of bladder cancer.

This systematic review and meta-analysis has several strengths. We included in the meta-analysis only studies with a clear definition of the exposure and outcomes. Of included studies, we conducted separate meta-analysis for pioglitazone use vs. no use, to acheive robust results. Several studies provide cumulative dose and duration of the pioglitazone exposure to find out the possible association with risk of bladder cancer.

Our systematic review and meta-analysis has several limitations. First, there was potential heterogeneity across the studies in the main analysis of bladder cancer. Heterogeneity may be due to study design and lack of certain variables known to be associated with bladder cancer, such as smoking, occupational exposure, duration of diabetes, nephropathy, COPD, and urinary tract disease. Second, possible overlapping of the studies such as 6 studies $29,32,37-40$ uses NHI database (Taiwan), 2 studies $^{12,34}$ uses KPNC database (USA), 2 studies $^{30,36}$ uses GPRD database (UK). Although, the duration of study, follow up, study design, patient population, definition of exposure, inclusion/exclusion criteria was different, so we included these studies for the meta-analysis for the pooled 


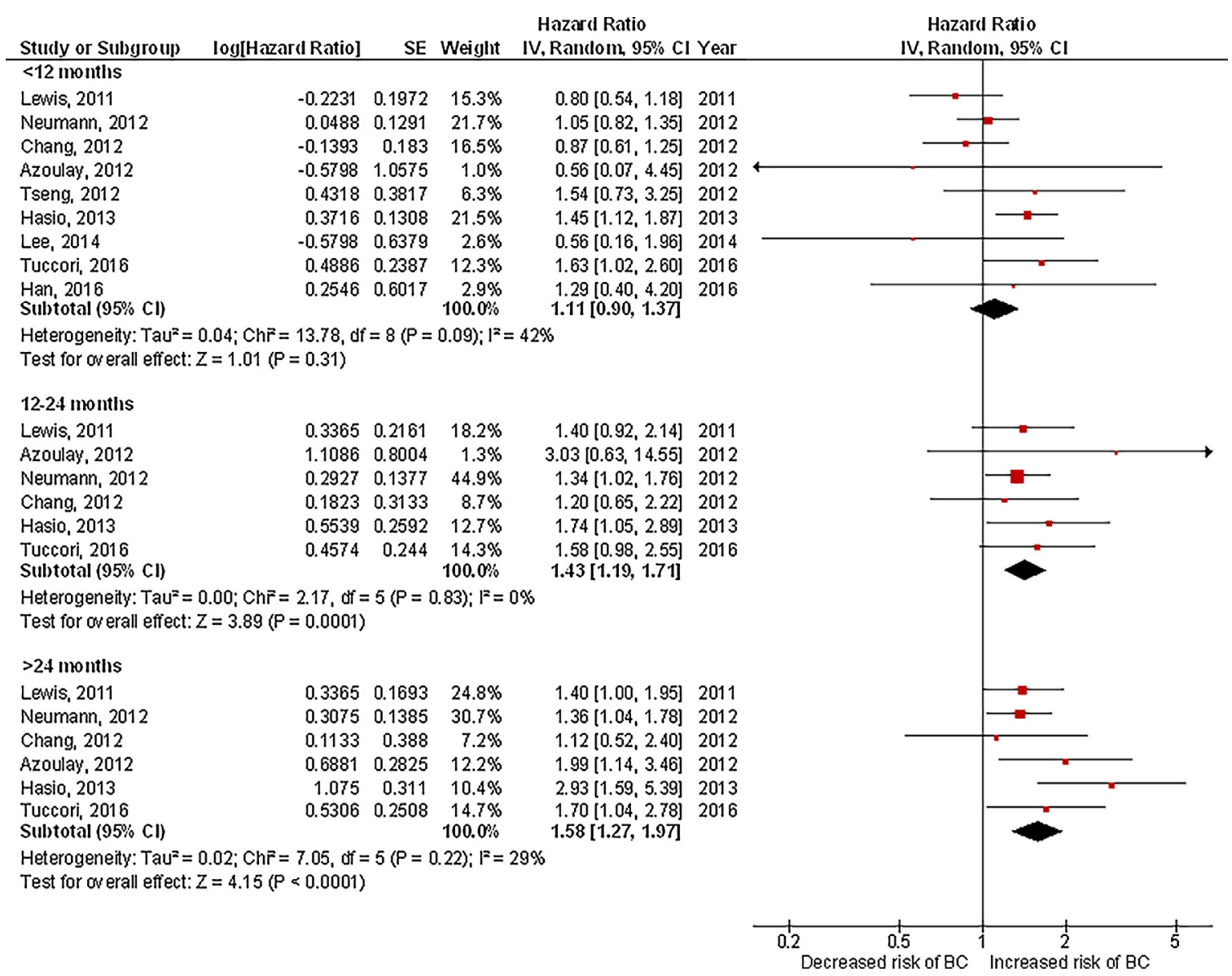

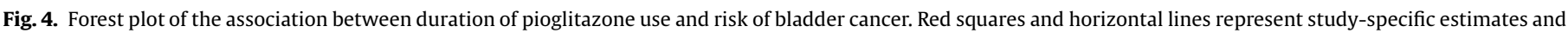

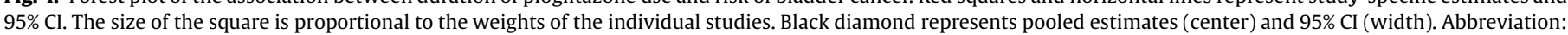
SE: standard error, IV: inverse variance, BC: bladder cancer.

estimates as these studies qualified for the inclusion in the analysis.

Our results could significantly influence the current clinical practice guideline in long term T2DM patients. However, to engrain the findings of our meta-analysis into clinical practice, high quality studies (randomized controlled trials/real world registries) with longer duration of follow up (especially designed to assess the effect of pioglitazone on bladder cancer in T2DM patients) is warranted. While we await further studies, clinicians should ensure that pioglitazone is judiciously prescribed especially patient subgroups with possible contraindications.

\section{Conclusion}

In conclusion, our study suggests that pioglitazone treatment was significantly associated with the risk of bladder cancer. Risk of bladder cancer appears to be associated with higher dose and longer duration of pioglitazone use. Literature is punctuated with evidence underlining association of bladder cancer with substantial morbidity and mortality. Because of inconsistent results riskbenefit analysis of pioglitazone use should be evaluated.

\section{Funding}

This research did not receive any specific grant from funding agencies in the public, commercial, or not-for-profit sectors.

\section{Conflict of interest}

None.

\section{Appendix A. Supplementary data}

Supplementary data associated with this article can be found, in the online version, at http://dx.doi.org/10.1016/j.cegh.2017.08.002.

\section{References}

1. Rizos CV, Kei A, Elisaf MS. The current role of thiazolidinediones in diabetes management. Arch Toxicol. 2016:90:1861-1881.

2. Xu X, Wu J, Mao Y, et al. Diabetes mellitus and risk of bladder cancer: a metaanalysis of cohort studies. PLoS One. 2013;8:e58079.

3. Garry EM, Buse JB, Lund JL, Pate V, Stürmer T. Comparative safety of pioglitazone versus clinically meaningful treatment alternatives concerning the risk of bladder cancer in older US adults with type 2 diabetes. Diabetes Obes Metab. 2017;1-1210.1111/dom.13049.

4. Mackenzie TA, Zaha R, Smith J, Karagas MR, Morden NE. Diabetes pharmacotherapies and bladder cancer: a medicare epidemiologic study. Diabetes Therapy. 2016;7:61-73.

5. Siegel RL, Miller KD, Jemal A. Cancer statistics, 2016. CA Cancer J Clin. 2016:66:7-30.

6. Dormandy JA, Charbonnel B, Eckland DJ, et al. Secondary prevention of macrovascular events in patients with type 2 diabetes in the PROactive Study (PROspective pioglitAzone Clinical Trial In macroVascular Events): a randomised controlled trial. Lancet. 2005;366:1279-1289.

7. Lubet RA, Fischer SM, Steele VE, Juliana MM, Desmond R, Rosiglitazone Grubbs CJ. A PPAR gamma agonist: potent promoter of hydroxybutyl(butyl) nitrosamine-induced urinary bladder cancers. Int J Cancer. 2008;123:22542259. 
8. Suzuki S, Arnold LL, Pennington KL, et al. Effects of pioglitazone, a peroxisome proliferator-activated receptor gamma agonist, on the urine and urothelium of the rat. Toxicol Sci. 2010;113:349-357.

9. Cohen SM. Effects of PPARgamma and combined agonists on the urinary tract of rats and other species. Toxicol Sci. 2005;87:322-327.

10. Hage JE. Toxicity profile of peroxisome proliferator activated receptor (PPAR) agonists and preclinical safety profile for muraglitazar. Endocrinologic and Metabolic Drugs Advisory Committee; 2005 [https://www.fda.gov/ downloads/AboutFDA/CentersOffices/CDER/ucm119071.pdf. Accessed 2 April 2017].

11. Hiatt WR, Kaul S, Smith RJ. The cardiovascular safety of diabetes drugsinsights from the rosiglitazone experience. N Engl J Med. 2013;369:1285-1287.

12. Lewis JD, Ferrara A, Peng T, et al. Risk of bladder cancer among diabetic patients treated with pioglitazone: interim report of a longitudinal cohort study. Diabetes Care. 2011;34:916-922.

13. Food and Drug Administration. FDA drug safety communication: updated drug labels for pioglitazone-containing medicines. [http://www.fda.gov/Drugs/ DrugSafety/ucm266555.htm. Accessed 2 April 2017].

14. Neumann A, Weill A, Ricordeau P, Fagot JP, Alla F, Allemand H. Pioglitazone and risk of bladder cancer among diabetic patients in France: a population-based cohort study. Diabetologia. 2012;55:1953-1962.

15. European Medicines Agency. Questions and answers on the review of pioglitazone containing medicines (Actos, Glustin, Competact, Glubrava and Tandemact). [http://www.ema.europa.eu/docs/en_GB/document_library/ Medicine_QA/2011/07/WC500109179.pdf. Accessed 2 April 2017].

16. Gupta S, Gupta K, Ravi R, et al. Pioglitazone and the risk of bladder cancer: an Indian retrospective cohort study. Indian J Endocrinol Metab. 2015;19:639-643.

17. Central Drugs Standard Control Organization. Minutes of the 64 th Meeting of Drugs Technical Advisory Board. [http://www.cdsco.nic.in/writereaddata/ Minutes\%20of\%2064th\%20DTAB\%20meeting. Accessed 5 April 2017].

18. Adil M, Venkata SK, Kandhare AD, Ghosh P, Sharma M. Thiazolidinediones and risk of bladder cancer in type 2 diabetes mellitus patients: a systematic literature review and meta-analysis of observational studies using real-world data. PROSPERO:CRD42016048729. [http://www.crd.york.ac.uk/PROSPERO/ display_record.asp?ID=CRD42016048729. Accessed 5 April 2017].

19. Moher D, Liberati A, Tetzlaff J, Altman DG. Preferred reporting items for systematic reviews and meta-analyses: the PRISMA statement. BMJ. 2009;339.

20. Wells GA, Shea B, O'Connell D, et al. The Newcastle-Ottawa Scale (NOS) for Assessing the Quality of Non-randomized Studies in Meta-analyses. [www.ohri. ca/programs/clinical_epidemiology/oxford.htm. Accessed 5 April 2017].

21. Deeks JJ, Higgins J, Altman D. Chapter 9: Analysing data and undertaking metaanalyses. In: Higgins JP, Green S, eds. Cochrane Handbook for Systematic Reviews of Interventions Version 5.1. 0 [updated March 2011]. The Cochrane Collaboration; 2011.

22. Kirkwood BR, Sterne JA. Second ed.. Essential Medical Statistics. Oxford: Blackwell Science; 2003.

23. DerSimonian R, Laird N. Meta-analysis in clinical trials. Control Clin Trials. 1986;7:177-188.

24. Higgins JP, Green S. Cochrane Handbook for Systematic Reviews of Interventions Version 5.1.0 [updated March 2011]. The Cochrane Collaboration; 2011.

25. Begg CB, Madhuchhanda M. Operating characteristics of a rank correlation test for publication bias. Biometrics. 1994;1088-1101.

26. Egger MS, Davey Smith G, Schneider M, Minder C. Bias in meta-analysis detected by a simple, graphical test. BMJ. 1997;315:629-634.

27. Schwarzer G, Carpenter JR, Rücker G. Meta-analysis with R. Springer; 2015.

28. Mamtani R, Haynes K, Bilker WB, et al. Association between longer therapy with thiazolidinediones and risk of bladder cancer: a cohort study. J Natl Cancer Inst. 2012;104:1411-1421.
29. Tseng $\mathrm{CH}$. Pioglitazone and bladder cancer: a population-based study of Taiwanese. Diabetes Care. 2012;35:278-280.

30. Wei L, MacDonald TM, Mackenzie IS. Pioglitazone and bladder cancer: a propensity score matched cohort study. Br J Clin Pharmacol. 2013;75:254-259.

31. Fujimoto K, Hamamoto Y, Honjo S, et al. Possible link of pioglitazone with bladder cancer in Japanese patients with type 2 diabetes. Diabetes Res Clin Pract. 2013;99:e21-e23.

32. Lee MY, Hsiao PJ, Yang YH, Lin KD, Shin SJ. The association of pioglitazone and urinary tract disease in type 2 diabetic Taiwanese: bladder cancer and chronic kidney disease. PLoS One. 2014;9:e85479.

33. Jin SM, Song SO, Jung $\mathrm{CH}$, et al. Risk of bladder cancer among patients with diabetes treated with a $15 \mathrm{mg}$ pioglitazone dose in Korea: a multi-center retrospective cohort study. J Korean Med Sci. 2014;29:238-242.

34. Lewis JD, Habel LA, Quesenberry CP, et al. Pioglitazone use and risk of bladder cancer and other common cancers in persons with diabetes. JAMA. 2015;314:265-277.

35. Tuccori M, Filion KB, Yin H, Yu OH, Platt RW, Azoulay L. Pioglitazone use and risk of bladder cancer: population based cohort study. BMJ. 2016;352:i1541.

36. Azoulay L, Yin H, Filion KB, et al. The use of pioglitazone and the risk of bladder cancer in people with type 2 diabetes: nested case-control study. BMJ. 2012;344:e3645.

37. Chang $\mathrm{CH}$, Lin JW, Wu LC, Lai MS, Chuang LM, Chan KA. Association of thiazolidinediones with liver cancer and colorectal cancer in type 2 diabetes mellitus. Hepatology. 2012;55:1462-1472.

38. Hsiao FY, Hsieh PH, Huang WF, Tsai YW, Gau CS, Risk of bladder cancer in diabetic patients treated with rosiglitazone or pioglitazone: a nested casecontrol study. Drug Saf. 2013;36:643-649.

39. Kuo HW, Tiao MM, Ho SC, Yang CY. Pioglitazone use and the risk of bladder cancer. Kaohsiung J Med Sci. 2014;30:94-97.

40. Han E, Jang SY, Kim G, et al. Rosiglitazone use and the risk of bladder cancer in patients with type 2 diabetes. Medicine (Baltimore). 2016;95:e2786.

41. Song SO, Kim KJ, Lee BW, Kang ES, Cha BS, Lee HC. The risk of bladder cancer in korean diabetic subjects treated with pioglitazone. Diabetes Metab J. 2012;36:371-378.

42. Ondrey F. Peroxisome proliferator-activated receptor gamma pathway targeting in carcinogenesis: implications for chemoprevention. Clin Cancer Res. 2009;15:2-8.

43. Saez E, Tontonoz P, Nelson MC, et al. Activators of the nuclear recepto PPARgamma enhance colon polyp formation. Nat Med. 1998;4:1058-1061.

44. Masaoka $\mathrm{H}$, Matsuo $\mathrm{K}$, Ito $\mathrm{H}$, et al. Cigarette smoking and bladder cancer risk: an evaluation based on a systematic review of epidemiologic evidence in the Japanese population. Jpn J Clin Oncol. 2016;46:273-283.

45. Yan L, Chen P, Chen E, Gu A, Jiang Z. Risk of bladder cancer in renal transplant recipients: a meta-analysis. Br J Cancer. 2014;110:1871-1877.

46. Lewis JD, Habel L, Quesenberry C, et al. Proteinuria testing among patients with diabetes mellitus is associated with bladder cancer diagnosis: potential for unmeasured confounding in studies of pioglitazone and bladder cancer Pharmacoepidemiol Drug Saf. 2014;23:636-645.

47. Korhonen P, Heintjes EM, Williams R, et al. Pioglitazone use and risk of bladder cancer in patients with type 2 diabetes: retrospective cohort study using datasets from four European countries. BMJ. 2016;354:i3903.

48. Lin HC, Hsu YT, Kachingwe BH, Hsu CY, Uang YS, Wang LH. Dose effect of thiazolidinedione on cancer risk in type 2 diabetes mellitus patients: a six-year population-based cohort study. J Clin Pharm Ther. 2014;39:354-360.

49. Turner RM, Kwok CS, Chen-Turner C, Maduakor CA, Singh S, Loke YK. Thiazolidinediones and associated risk of bladder cancer: a systematic review and meta-analysis. BrJ Clin Pharmacol. 2014;78:258-273. 